\title{
Pneumonia-related ideations, care-seeking, and treatment behaviors among children under 2 years with pneumonia symptoms in northwestern Nigeria
}

Udochisom Anaba

Paul L. Hutchinson

Dele Abegunde

Emily White Johansson

Follow this and additional works at: https://knowledgecommons.popcouncil.org/departments_sbsr-pgy How does access to this work benefit you? Let us know!

\section{Recommended Citation}

Anaba, Udochisom, Paul L. Hutchinson, Dele Abegunde, and Emily White Johansson. 2020. "Pneumoniarelated ideations, care-seeking, and treatment behaviors among children under 2 years with pneumonia symptoms in northwestern Nigeria," Breakthrough RESEARCH brief. Washington, DC: Population Council. Version of record: https://doi.org/10.1002/ppul.24644. 


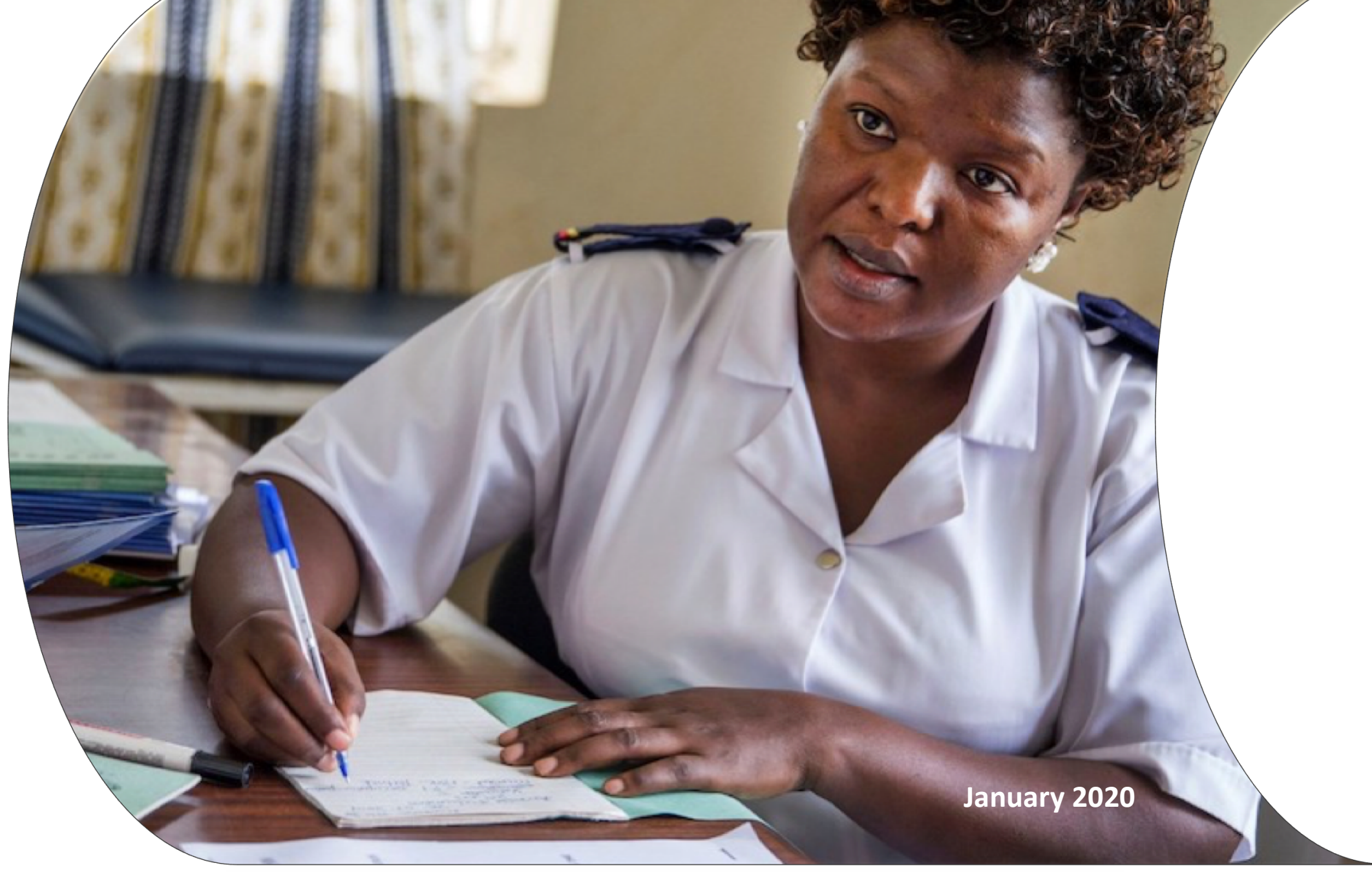

\section{Research brief}

Pneumonia-related ideations, care-seeking, and treatment behaviors among children under 2 years with pneumonia symptoms in northwestern Nigeria

Udochisom Anaba, MPH Paul L. Hutchinson, PhD Dele Abegunde, MD Emily White Johansson, PhD 


\section{This analysis was published in Pediatric Pulmonology in a special journal issue on "Pediatric Pneumonia in Nigeria" that was launched at the Global Conference on Childhood Pneumonia on 29 - 31 January 2020.}

Pneumonia remains the leading infectious cause of child mortality worldwide despite declines in pneumonia-related child mortality rates since 2000 globally ${ }^{1}$. In Nigeria, approximately 134000 deaths among children under 5 years were due to pneumonia in 2017.2 Prompt treatment of pediatric pneumonia symptoms is a cornerstone of child survival programs but remains a challenge in Nigeria. Psychosocial influences, or ideations, directly influence pathways to care but have not been previously measured or examined for pediatric pneumonia.

\section{Conceptual Framework}

Kincaid's Ideation Model of Strategic Communication and Behavior Change theorizes that psychosocial influences, or ideations, are intermediate determinants that help catalyze a person's decision to engage in a specific action such as care-seeking or treatment for pneumonia symptoms. ${ }^{3}$

In this model, ideations consist of three main domainscognitive, emotional and social- and each contain specific psychosocial influences including knowledge, attitudes, beliefs, self-efficacy, perceived risk, subjective norms, and self-image (cognitive); emotional response, empathy, and self-efficacy (emotional); and social support, social influence, interpersonal communication, and personal advocacy (social). We used this model to guide the development of ideational metrics for pediatric pneumonia care-seeking and treatment behaviors (Figure 1). In this analysis, we aimed to develop a set of pneumonia-related ideational factors and to examine the extent of their associations with care-seeking from formal medical sources and antibiotic use for children under 2 years with pneumonia symptoms in northwestern Nigeria.

\section{Methods}

A two-stage cluster-sample cross-sectional populationbased survey was conducted in Kebbi, Sokoto, and Zamfara States in September 2019. Across 108 enumeration areas, all households were enumerated to census pregnant women and randomly sample women with children under 2 years ("under-twos") for inclusion. Respondents were asked about pediatric pneumonia and other health-related behaviors and ideations developed using the Ideation Model of Strategic Communication and Behavior Change. Prevalence ratios for predictors of care-seeking from formal medical sources and antibiotic treatment for pneumonia symptoms among under-twos were calculated using mixed-effects Poisson regression models with robust error variance.

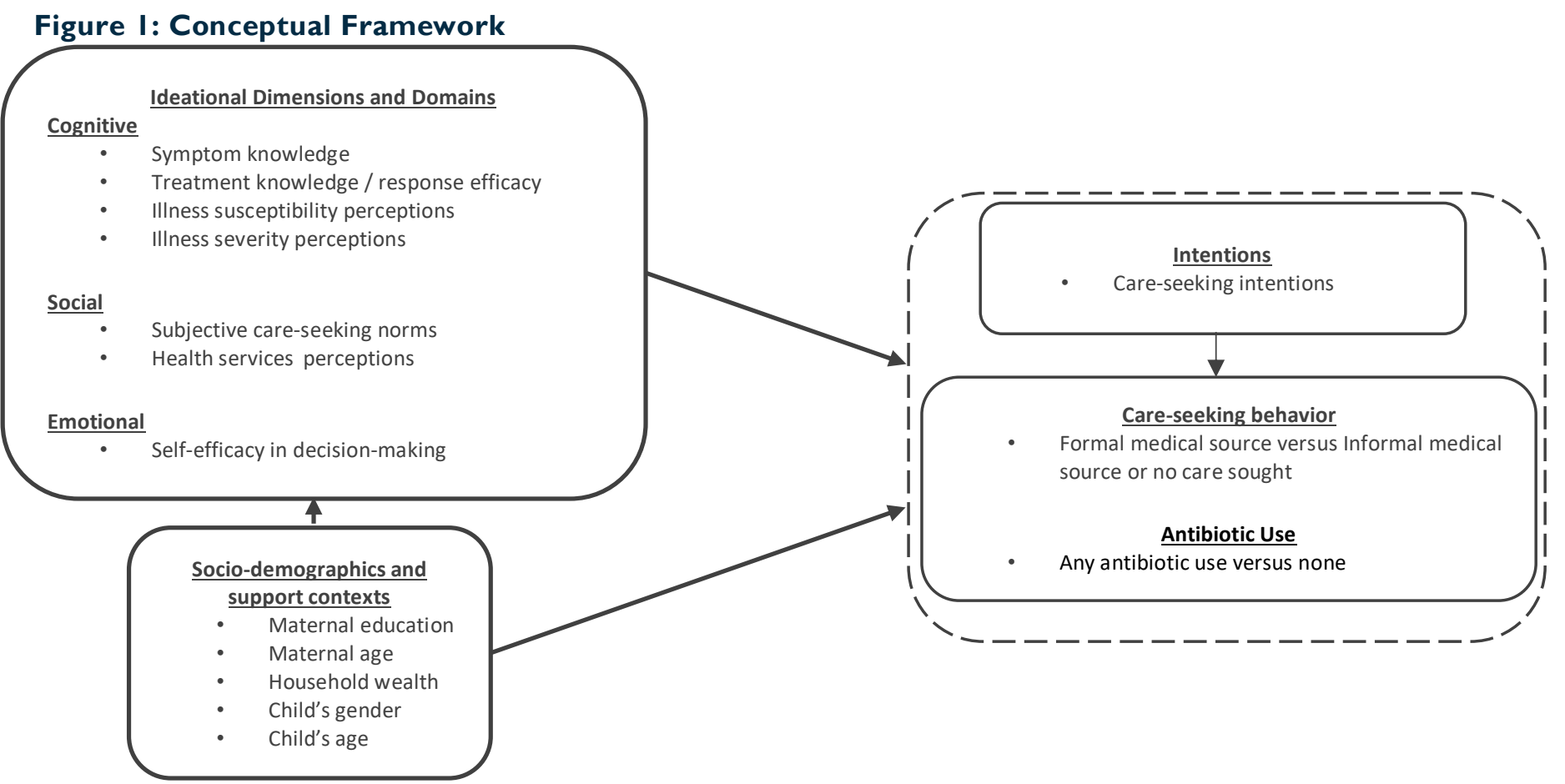


Among 350 under-twos with pneumonia symptoms, 33.8\% were taken to formal medical care and $38.0 \%$ used antibiotics. Women who positively viewed treatment efficacy and those who positively viewed health services quality had 1.35 (95\% Cl: 1.00-1.82; P=0.050) and 2.13 (95\% $\mathrm{Cl}$ : 1.35-3.35; $\mathrm{P}=0.001)$ times higher likelihood of attending formal medical sources, while women viewing peers as mostly attending drug shops had 29\% lower likelihood (Table 1). Caregivers were also significantly less likely to seek formal medical care for infants 0 to 5 months with pneumonia symptoms than for older children aged 12 to 23 months $(0.66,95 \% \mathrm{Cl}: 0.44-0.99, \mathrm{P}=0.040)$. For antibiotic use, perceived treatment efficacy and illness susceptibility were significant predictors (Table 2). Lastly, children living in the richest households were $45 \%$ more likely to receive antibiotics for pneumonia symptoms than those living in the poorest households $(1.45,95 \% \mathrm{Cl}$ : 108-1.94; $\mathrm{P}=.010)$.
We found low levels of care-seeking from formal medical sources $(33.8 \%)$ and antibiotic use (38.0\%) among children under 2 years with pneumonia symptoms in study areas. Behavioral outcomes were significantly associated with psychosocial influences, or ideations, related to maternal beliefs about treatment efficacy, health services quality, social norms, and perceived illness severity and susceptibility after adjustment for sociodemographics. Findings suggest that programs focusing on increasing pneumonia knowledge alone may not be sufficient to improve care-seeking and treatment rates, and should expand to address perceived and actual poor-quality health services and maternal beliefs about treatment efficacy, social norms, illness severity and susceptibility. Ideational metrics provide program-relevant insights about beliefs or perceptions that may impede behavioral change needed to reduce deaths from this leading cause of child mortality.

Table I: Ideational predictors of formal care-seeking for pediatric pneumonia symptoms among under-twos

\begin{tabular}{|c|c|c|c|c|c|}
\hline Domain & Likert-scale question & Response & Prevalence ratio & $95 \% \mathrm{Cl}$ & pvalue \\
\hline \multirow{2}{*}{$\begin{array}{l}\text { Health } \\
\text { services } \\
\text { perception }\end{array}$} & \multirow{2}{*}{$\begin{array}{l}\text { Health facilities in my community frequently } \\
\text { have treatments needed for sick children }\end{array}$} & Agree & 2.13 & $1.35-3.35$ & 0.001 \\
\hline & & Disagree & I.00 (Reference) & & \\
\hline \multirow{2}{*}{$\begin{array}{l}\text { Treatment } \\
\text { knowledge / } \\
\text { response } \\
\text { efficacy }\end{array}$} & \multirow{2}{*}{$\begin{array}{l}\text { Spontaneously reported that antibiotics are } \\
\text { effective in treating pediatric pneumonia }\end{array}$} & Yes & 1.35 & $1.00-1.82$ & 0.050 \\
\hline & & No & I.OO (Reference) & & \\
\hline \multirow{2}{*}{$\begin{array}{l}\text { Subjective } \\
\text { care-seeking } \\
\text { norms }\end{array}$} & \multirow{2}{*}{$\begin{array}{l}\text { Most women in this community would go to } \\
\text { a drug shop or traditional provider for } \\
\text { pediatric pneumonia symptoms before } \\
\text { visiting a facility }\end{array}$} & Agree & 0.71 & $0.52-0.97$ & 0.030 \\
\hline & & Disagree & I.00 (Reference) & & \\
\hline
\end{tabular}

* Likert scale are defined as agree (strongly or somewhat) and disagree (strongly or somewhat)

Table 2: Ideational predictors of antibiotic use for pediatric pneumonia symptoms among under-twos

\begin{tabular}{|c|c|c|c|c|c|}
\hline Domain & Likert-scale question & Response & Prevalence ratio & $95 \% \mathrm{Cl}$ & pvalue \\
\hline \multirow{2}{*}{$\begin{array}{l}\text { Treatment } \\
\text { knowledge / } \\
\text { response } \\
\text { efficacy }\end{array}$} & \multirow{2}{*}{$\begin{array}{l}\text { Spontaneously reported that antibiotics are } \\
\text { effective in treating pediatric pneumonia }\end{array}$} & Yes & 1.86 & I. $26-2.74$ & 0.002 \\
\hline & & No & 1.00 (Reference) & & \\
\hline \multirow{2}{*}{$\begin{array}{l}\text { Illness } \\
\text { susceptibility }\end{array}$} & \multirow{2}{*}{ Only weak children die from pneumonia } & Agree & 0.71 & $0.52-0.98$ & 0.040 \\
\hline & & Disagree & I.00 (Reference) & & \\
\hline
\end{tabular}

* Likert scale are defined as agree (strongly or somewhat) and disagree (strongly or somewhat) 


\section{References}

1. Howie SRC, Murdoch DR. Global childhood pneumonia: the good news, the bad news, and the way ahead. Lancet Global Health. 2019;7(1):e4-e5.

2. McAllister DA, Liu L, Shi T, et al. Global, regional, and national estimates of pneumonia morbidity and mortality in children younger than 5 years between 2000 and 2015: a systematic analysis. Lancet Global Health. 2019;7(1):e47-e57.

3. Kincaid DL. Mass media, ideation, and behavior: a longitudinal analysis of contraceptive change in the Philippines. Commun Res. 2000;27(6):723-763.

\section{(E) USAID}

Breakthrough RESEARCH is made possible by the generous support of the American people through the United States Agency for International Development (USAID) under the terms of cooperative agreement no. AID-OAA-A-17-00018. The contents of this document are the sole responsibility of the Breakthrough RESEARCH and Population Council and do not necessarily reflect the views of USAID or the United States Government.

\section{Breakthrough RESEARCH FOR SOCIAL \& BEHAVIOR CHANGe}

Breakthrough RESEARCH catalyzes social and behavior change (SBC) by conducting state-of-the-art research and evaluation and promoting evidence-based solutions to improve health and development programs around the world. Breakthrough RESEARCH is a consortium led by the Population Council in partnership with Avenir Health, ideas42, Institute for Reproductive Health at Georgetown University, Population Reference Bureau, and Tulane University.

(C) 2020 The Population Council. All rights reserved.

Cover photo by Population Council.

Principal Investigator \& Research Lead: Paul L Hutchinson

\section{Citation}

Anaba U, Hutchinson PL, Abegunde D, White Johansson E. Pneumonia-related ideations, care-seeking, and treatment behaviors among children under 2 years with pneumonia symptoms in northwestern Nigeria. Pediatric Pulmonology. 2020;1-13.

\section{Contact}

Breakthrough RESEARCH/Nigeria. Plot 839 Idris Ibrahim Crescent, Jabi, Abuja, Nigeria. breakthroughactionandresearch.org 